\title{
Power System Studies in the Clean Energy Era: From Capacity to Flexibility Adequacy Through Research and Innovation
}

\author{
Vasiliki Vita $^{1(\bowtie)}$, Elias Zafiropoulos ${ }^{1}$, Ioannis F. Gonos ${ }^{1}$, \\ Valeri Mladenov², and Veselin Chobanov ${ }^{2}$ \\ 1 Institute of Communications and Computer Systems, \\ 9 Iroon Polytechniou Street, 15780 Athens, Greece \\ vasvita@aspete.gr \\ 2 Technical University of Sofia, 8 KL. Ochridski Blvd., 1000 Sofia, Bulgaria
}

\begin{abstract}
A secure and reliable supply of electricity is a necessary requirement of a well-functioning economy. Reducing the likelihood of system disturbances or, in the extreme, load (demand) shedding is a fundamental objective of Transmission System Operators during planning and operation of electricity grids. The integration of new forms of generation - diverse in location and operation profile - as well as rapidly changing demand from new consumer technologies powered by breakthroughs in technology, poses a different set of challenges in their daily business. System flexibility, like many other aspects of the bulk electric system, can be examined as a supply and demand problem. A holistic assessment of flexibility examines the resources available to supply flexibility and the factors driving the demand or requirements for flexibility. This paper aims to highlight the importance of flexibility assessment studies alongside capacity adequacy studies being carried out during system planning. Moreover, the paper will present the challenges facing the electricity networks for integrating high amount of renewable energy which are well expressed by the views of the energy stakeholders regarding priorities for innovation technologies and this is also very well reflected in the research and development projects. The FLEXITRANSTORE project, which is aiming to implement innovative technologies of battery storage solutions, smart grid technologies and market platforms in the SEE region, is briefly presented. Furthermore, a wide review of flexibility-related research and innovation projects in Europe and United States has been carried out during the project and their contribution is presented, analysed and mapped against specific power system challenges. A detailed survey conducted during FLEXITRANSTORE on identifying stakeholders' opinion on electricity networks' challenges is presented and commented. Stakeholders' are stressing that highest priorities for the electricity networks in their country are renewable energy integration, cross border interconnections, grid stability in short- and long-term horizon. These renewables integration and cross border interconnections answers could be also linked with the European targets: To sum up, the paper is identifying significant opportunities for future research and innovation in storage and market models, regarding the inherent flexibility of the electricity networks to host the electrification 'wave' of the following decades.
\end{abstract}


Keywords: Flexibility $\cdot$ FLEXITRANSTORE project $\cdot$ Power systems ·

Transmission systems operators

\section{Introduction}

Planning and operation of modern electric power systems comprehend several complex and interlinked tasks. These tasks can be divided in three main groups, depending on the considered time horizon: (i) Long-term resource and equipment planning, which targets time ranges from one year to several decades. Examples are investment planning, transmission and distribution planning and long range fuel planning, (ii) Shortterm operational scheduling, which is used for time intervals from several hours to a few weeks, or even year(s). Examples are unit commitment (UC) scheduling, maintenance and production scheduling and fuel scheduling, (iii) Real time operations, which consider fractions of a second to several minutes [1, 2].

Concern for the environment and energy security, as well as rising fuel prices, have led to significant, sustained growth of wind and solar electricity generation capacity in Europe and worldwide. The difficulty posed by the integration of these variable resources into existing power systems varies according to the production and scale of the variable resource, its correlation with system load, and the flexibility of the power system in question. Flexibility can be defined as the ability of a system to deploy its resources to respond to changes in net load, where net load is defined as the remaining system load not served by variable generation [3-5]. The impact of RES on the different time scales is depicted in Fig. 1.

Capacity adequacy studies have addressed the question of how much capacity is required to reliably meet system load, at a certain point in time, but have not considered whether the system's planned resources could be operated in a sufficiently flexible manner. These studies are key tasks for regulatory bodies, who look to ensure that market designs deliver in the long run, or for vertically integrated utilities, ensuring the suitability of a planned plant portfolio before more detailed engineering and operational analyses are carried out. Investors and plant manufacturers also have an interest in the cycling requirements experienced by potential investments. Variable renewables (VRES) integration studies have also required enhanced simulation and modeling tools. The adaptation of unit commitment to a stochastic [6] and rolling framework, and the inclusion of VRES forecasts [7] can provide an insight into how systems might operate under high a variable generation penetration.

This paper aims to highlight the importance of flexibility assessment studies alongside capacity adequacy studies being carried out during system planning. The challenges facing the electricity networks for integrating high amount of renewable energy are well reflected in the views of the energy stakeholders regarding priorities for innovation technologies and this is also very well reflected in the R\&D projects. To sum up, the paper is identifying opportunities for future research and innovation regarding the inherent flexibility of the electricity networks to host the electrification 'wave' of the following decades. 


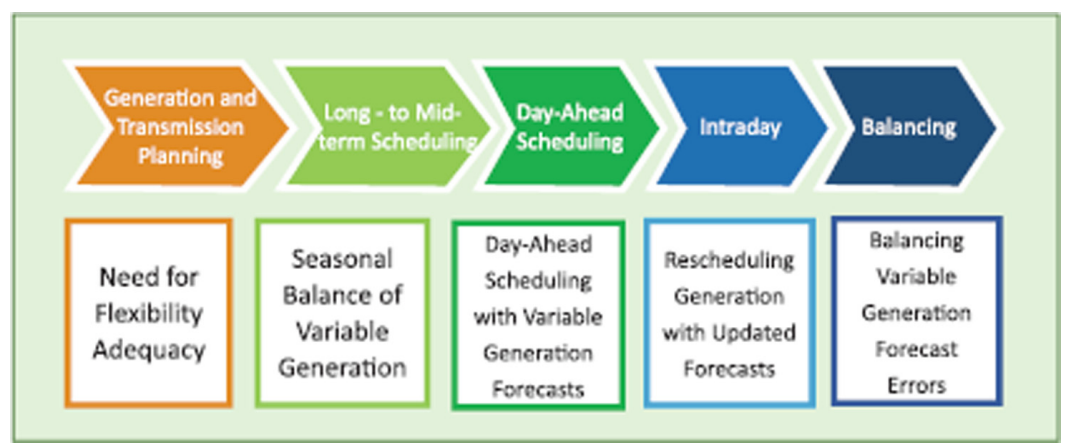

Fig. 1. Impacts of intermittent RES on different timescales of power system operation [3, 4].

\section{The Need for Flexibility Assessment}

Since the construction of a new generation facility has a multi-year lead time, traditional long-term planning is required to ensure the future reliability of power systems. The Capacity Adequacy Forecast (CAF) has been assessing the capacity adequacy of available supply resources to meet simulated demand scenarios. This annual exercise provides an overview of the state-of-play across a ten-year time frame, carried out by national TSOs for each country and ENTSOe for the European network [8]. Ten years is usually the time frame during which policy makers, investors and market participants make strategic decisions so as to allow the power system to deliver a targeted level of adequacy. Such forecasting exercises focus on the likelihood of unusual events disrupting supply. The results are derived from many simulations providing a probabilistic interpretation of the likelihood of lack of supply. One such metric explored in the CAF and covered here, is loss-of-load expectation (LOLE). Simply put, it is the average number of hours per year in which it is statistically expected that there is not sufficient power supply in the market to cover demand. Note that this is not translated in a blackout as the analysis keeps security margin for unforeseen events near real time, since it is a probabilistic assessment based on models.

Adequacy is not only related to the total amount of capacity being installed in the system, but also to the ability of the installed capacity to adjust to the ever-increasing dynamics of dispatch events in the system. The latter is defined as flexibility adequacy and it becomes ever more important, mainly due to the increasing amount of variable renewable energy present in the power system $[1,5]$. Several flexibility services will be required in order to ensure a smooth transition to high RES penetration, particularly:

- Ramping needs: With the high RES penetration, flexible resources will become essential to meet the fast change of residual demand i.e. the steep upward ramp created by the decline in solar output due to the sun setting when demand increases in the evening.

- Balancing fast reserves: The increase of variable generation along with the forecast error of wind and PV should be overcome with reserve deployment in order to secure the supply. Modelling of balancing reserves in the CAF is performed 
assuming that a fixed amount of supply is kept available at any time. Despite the considerable improvements in forecasting variable power generation, for both wind and solar, in practice, forecasting can never be perfectly accurate, with decreasing forecast errors as real-time operation moment approaches. Thus, forecasts are very likely to be updated hours ahead of real time, and the system will require fast starting and controllable resources (interconnectors, demand side response, storage and fast response generators). It is easy to imagine that the larger the ramps the bigger the need for flexibility.

Recent studies in Europe and around the world confirm that flexibility is becoming a crucial point for system adequacy. Flexibility services and products are growing in importance and are progressively being integrated into the market. The ramping needs already play a central role in US electricity markets and flexibility services are being designed and implemented in European markets. This tendency towards flexibility services is more than evident in the Research \& Innovation efforts in Europe and US [2, 9, 10].

\section{Flexibility Research and Innovation in the Horizon 2020 Context: The FLEXITRANSTORE Project}

Identifying the aforementioned challenges for, several European R\&D projects and Innovation Actions have been working intensely on the issues of integrating renewable energy technology into the electricity grids. Looking into the European and US projects related with RES integration and flexibility issues, as these have been identified in [11], interesting remarks may come out:

(a) Extensive applications of Distributed Energy Resources (DER) integration are being developed and implemented in real life scenarios. They focus mostly on the balancing and congestion challenges, voltage/frequency regulation and stability, communications infrastructure, smart energy management, micro-generation and distributed storage. There are very few applications studying market solutions for integrating DER through providing flexibility services and remuneration mechanisms.

(b) Among the various flexibility related EU projects, the distribution grids, local electricity networks and microgrids have been very popular for technology demonstrations. Large scale technology solutions in transmission networks have been demonstrated in few European projects, focusing either on improving grid assets efficiency and promoting HVDC technology (BESTPATHS), or on developing simulation platforms on market, real time system operation or crossborder trading (FUTUREFLOW, CROSSBOW). Flexibility assessment frameworks for transmission networks, bridging technology innovations, system simulation methodology and market reforms proposals, have not been the main driver in EU research programs so far. 
(c) Storage related European projects have been targeting mainly to the LV-MV level i.e., battery storage in building blocks, residential thermal storage or local RESstorage. Thus, the related flexibility services have been demonstrated at the distribution level with no clear plan for upscaling to the transmission system

(d) On the other side of the Atlantic, research and innovation projects in the US are closely related to the new technologies developed by the power equipment manufacturers. Selective products are chosen to be demonstrated in projects to promote industrial innovation and focus greatly on developing new business models and revenue streams. That is to say, while promoting grid operation benefits for flexibility, the majority of projects depend greatly on the respective business prospects.

(e) Energy storage plays a key role in the modernization of the US power grid [10]. Several storage projects with variable scales have been implemented in the US electricity networks, while the US market regimes promote the provision and remuneration of storage related grid services, such as frequency regulation, power balancing, black start capability, smoothing, load shifting, ramp management, energy price arbitrage. An example is the PJM RTO, which structures its frequency regulation market so that energy storage is compensated for the speed and accuracy it can provide to the system [9].

(f) These energy storage projects include a variety of RES-plus-storage applications. Significant large scale projects of wind generation coordinated with battery storage have been commissioned in the US, such as the Tehachapi project [12]. The wind-storage demonstrates the aforementioned services, as well as further support in the respective area of Southern California with high wind capacity: load shed deferral for increasing system reliability of supply, renewable-energyrelated transmission optimization, transmission congestion issues mitigation.

(g) Electric Power Research Institute (EPRI) has been developing a system flexibility assessment tool InFLEXIon, currently version 3.0. This software tool was developed in the context of a research program led by EPRI and can assist planners in assessing operational flexibility of electric power systems, analysing system requirements for supply-demand energy balancing, supporting long-term generation and transmission planning [13].

(h) Additionally, the International Energy Association (IEA) has developed FAST and FAST2 tools in the context of "The Grid Integration of Variable Renewables (GIVAR)" undertaken by the IEA to address the critical question of how to balance power systems featuring large shares of VRE. Several countries worldwide were studied and significant results were presented in the respective reports [14].

The aforementioned review was conducted in the context of an ongoing Innovation Action Project FLEXITRANSTORE and the results of the survey are mapped in Table 1. The project FLEXITRANSTORE has launched its activities in November 2017 and will focus on demonstrating transmission grid innovative technologies that improve flexibility in the SEE power system area.

Grid scale storage at the HV/MV substations and respective efficient controllers will be demonstrated for two different applications: TSO-DSO coordination, depicting 
Table 1. Flexibility related EU-funded projects and their topics of interest

\begin{tabular}{|c|c|c|c|c|c|c|c|c|c|c|c|c|c|c|c|c|c|}
\hline & $\begin{array}{c}\text { Objectives/ } \\
\text { Research Areas }\end{array}$ & 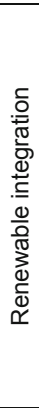 & 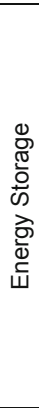 & 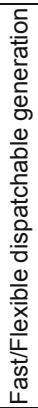 & 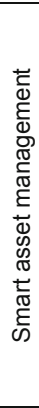 & 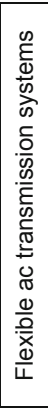 & 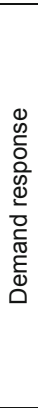 & 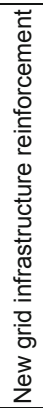 & 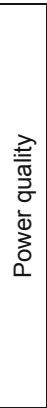 & 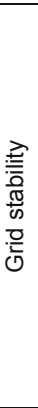 & 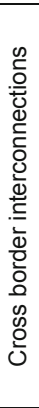 & 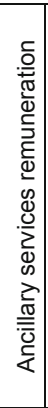 & 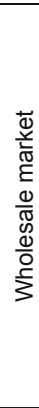 & 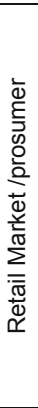 & 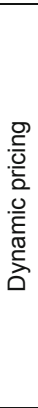 & 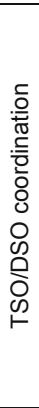 & 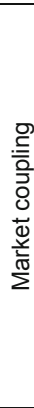 \\
\hline & SMARTNET & & v & & & & & & & & v & & v & & v & v & \\
\hline & ELSA & & v & v & & & & V & v & v & & & & & & & \\
\hline & FLEX4GRID & & & & & & & $v$ & & & & & & $v$ & & & V \\
\hline & EMPOWER & & & v & & & & $v$ & & & & & & v & & & v \\
\hline & ENERGISE & & & & & & V & $v$ & & & & & & & & & \\
\hline & UPGRID & & & v & & & V & & & v & v & & & v & & & \\
\hline & MIGRATE & v & & $\checkmark$ & $\mathrm{V}$ & V & V & V & V & & & & & & & & \\
\hline & TILOS & v & & V & & & & & & v & & & & & & & \\
\hline & TRIANGULUM & & & & V & & V & V & & & & & & & & & v \\
\hline & SMARTER EMC2 & $v$ & & & & & V & & & v & & & & & & & v \\
\hline & IDE4L & & $v$ & & v & & V & v & V & $\checkmark$ & & & & $v$ & $v$ & & \\
\hline & GRID+STORAGE & & $v$ & & & & & & & & & & & & & $v$ & $v$ \\
\hline & VENTEEA & $\checkmark$ & & & & & & V & V & & & & & & & & \\
\hline & NETFFICIENT & $\checkmark$ & $v$ & $v$ & v & & & V & & $\checkmark$ & & & & $v$ & & & \\
\hline & NAIADES & & v & $v$ & & & & & & & & & & & & & \\
\hline & STORY & & $v$ & & v & & & $v$ & & & & & & & & & $v$ \\
\hline$\sum_{j}$ & FLEXMETER & & & 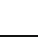 & $\mathrm{v}$ & & $\mathrm{v}$ & $v$ & & v & & & & v & & & $\mathrm{v}$ \\
\hline ช্요 & REALVALUE & & v & $v$ & & & & $\mathrm{v}$ & & & & & $v$ & & & & \\
\hline $\begin{array}{l}\mathbb{\pi} \\
5\end{array}$ & SENSIBLE & $v$ & $v$ & & v & & & $\mathrm{v}$ & & $\checkmark$ & & & & & & & $v$ \\
\hline 亗 & P2P SMARTTEST & & $v$ & & & & & 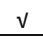 & & $v$ & & & & & & & $\mathrm{v}$ \\
\hline & STORE\&GO & $\checkmark$ & v & & & & & & & & & & & & & & \\
\hline & NOBEL GRID & & & & v & & & v & & & & & & $\mathrm{v}$ & & & \\
\hline & BESTPATHS & & & & V & & V & $v$ & v & & & & & & & $\mathrm{V}$ & \\
\hline & INDUSTRE & v & & & & & V & & & & & $v$ & $\checkmark$ & $\checkmark$ & v & & $v$ \\
\hline & FLEXICIENCY & & & & & & & $v$ & & & & $\checkmark$ & $\checkmark$ & v & & & $v$ \\
\hline & FUTUREFLOW & & & $v$ & & & v & & & $\checkmark$ & v & & $\checkmark$ & & & & $v$ \\
\hline & DAREED & $\checkmark$ & & & & & v & $v$ & & $\checkmark$ & & & & & & & $v$ \\
\hline & DISCERN & v & & & & & v & $v$ & $\checkmark$ & $v$ & & & & & & & \\
\hline & eBADGE & & & $v$ & & & v & & v & $v$ & & & & & & & $v$ \\
\hline & ANYPLACE & & v & & v & & v & $\mathrm{V}$ & & & & & $\checkmark$ & V & $v$ & & \\
\hline & ELECTRA & $\checkmark$ & & & & & v & & & $\checkmark$ & v & & $\checkmark$ & & & $\mathrm{V}$ & $v$ \\
\hline & INSPIRE-GRID & $v$ & & & & & & v & & & & & & & & & $v$ \\
\hline & HYBRID-VPP4DSO & $\checkmark$ & & V & V & & v & $v$ & & $\checkmark$ & & & & & & & \\
\hline & BESTRES & v & $v$ & $v$ & & & V & & & & & $v$ & $\checkmark$ & $v$ & & & $v$ \\
\hline & INTEGRID & v & & & & & v & & $\checkmark$ & $\checkmark$ & & $v$ & $v$ & & & & \\
\hline & PROMOTION & v & & & & $v$ & & $\mathrm{v}$ & $\checkmark$ & & $v$ & & & & & & \\
\hline & EVOLVDSO & v & & $v$ & & & & $v$ & & $\checkmark$ & & & & & $v$ & $\mathrm{v}$ & $v$ \\
\hline & INTERFLEX & $v$ & v & & $\mathrm{v}$ & & v & & & & & & & v & & & \\
\hline & GRID4EU & v & $v$ & & $\mathrm{v}$ & & v & & $\mathrm{v}$ & & & & & v & & & \\
\hline
\end{tabular}


demand side management flexibility potential and Wind-Storage configuration, promoting ancillary services of a 'near-dispatchable' nature. Business models and market platforms will be investigated and demonstrated respectively, and solutions will be proposed, especially for demand side management flexibility. The benefits of these projects will be related with flexibility adequacy studies in Greece, Bulgaria and Cyprus. In Table 1, brief statistics show that most popular topics are new equipment on the grid, demand response, RES integration, market coupling and grid stability. However, Cross border cooperation and TSO-DSO coordination need further attention by $R \& I$ community.

\section{Stakeholders' Opinion on Flexibility Challenges: Where We Are Today and Future Prospects-Aspirations}

In FLEXITRANSTORE, a questionnaire was launched to stakeholders asking their opinion in various aspects of flexibility as well as their interest on the specific technology innovations promoted in this project. During an almost 3-month period, 47 answers were received across Europe and across sectors including network operators, regulators and policy makers, market operators, ESCOs, aggregators, energy suppliers, power producers, manufacturers and research community.

The first 7 questions of the questionnaire cover a variety of issues on power system flexibility and electricity markets, giving the stakeholders the opportunity to express their opinions and limitations they face in their national and pan-European electricity sector. The answers provided excellent information on the current international technologies and assessment frameworks that are related with operational flexibility, and identifying the key concerns and misperceptions of the term. All answers stressed the importance of flexibility, beyond operational reliability, presenting examples of inflexibility in technical level and market level, emphasizing on the gaps and needs for flexibility assessment.

In the question 8, asking for the critical topics for the power system and electricity markets in a short and long term time horizon, with a rate of relevance, where $1=$ low relevance and $5=$ high relevance, the stakeholders had the chance to outline the power system challenges in a qualitative way. The outcomes were averaged and sorted accordingly in two separate diagrams shown side by side in Figs. 2 and 3. Furthermore, the answers of value 4 or 5 (meaning high relevance) have been allocated to the critical topics and the corresponding percentages are presented in Figs. 4 and 5.

According to stakeholders, highest priorities for the electricity networks in their country are renewable energy integration, cross border interconnections, grid stability in short and long term horizon. RES integration and cross border interconnections answers could be also linked with the European targets. Moreover, in short term horizon (up to 5 years) the wholesale markets and the ancillary services remuneration (market-related) are highly prioritized as critical topics. In the long term horizon (more than 5 years), energy storage and demand response are rising higher to the prioritization list of critical topics, since they are currently considered rather immature in Europe. Therefore, significant research and innovation are needed on these topics: 


\section{short term (Avg of all)}

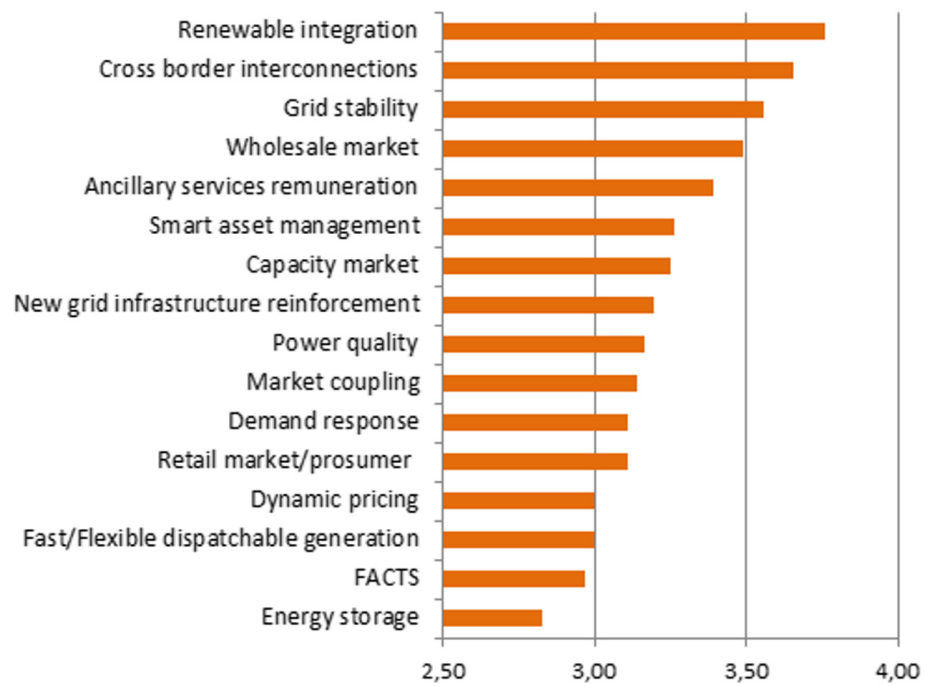

Fig. 2. Average value of relevance, according to stakeholders, on critical topics related to flexibility, in short (1-5 years) horizon.

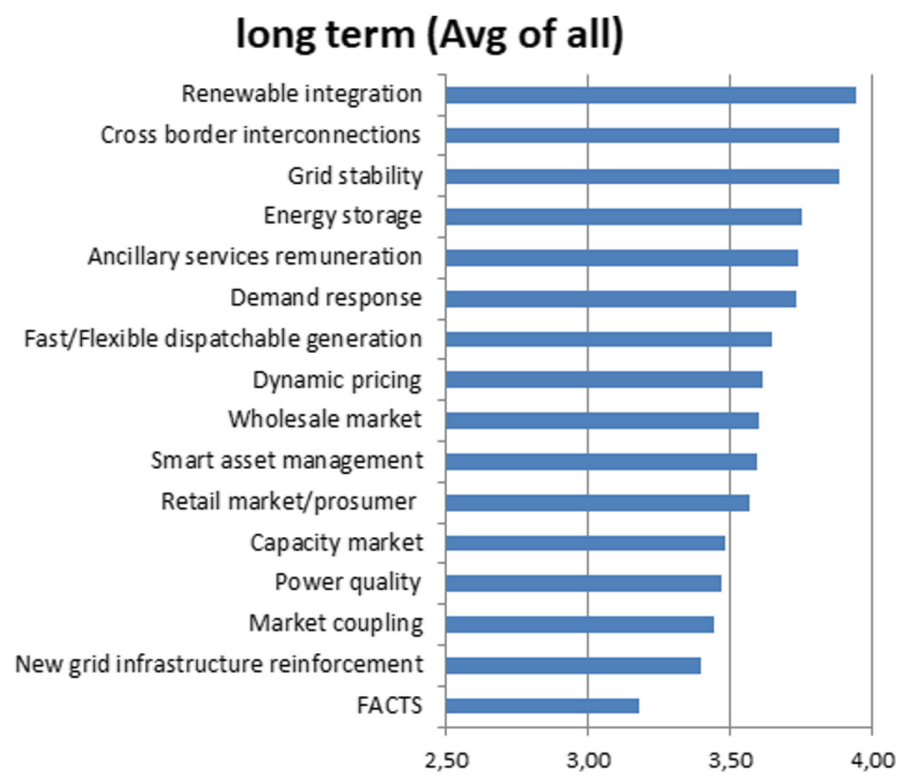

Fig. 3. Average value of relevance, according to stakeholders, on critical topics related to flexibility, in long (6-10 years) horizon. 


\section{short term (\% of answers 4 or 5 )}

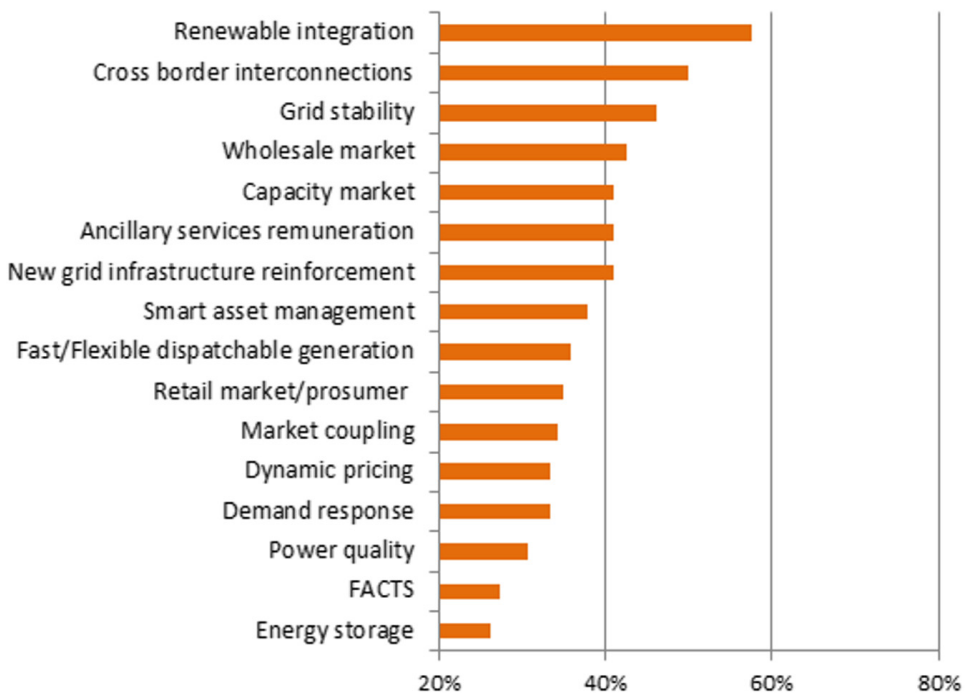

Fig. 4. Percentage of number with high relevance, according to stakeholders, over total answers on critical topics related to flexibility, in short (1-5 years) horizon.

\section{long term (\% of answers 4 or 5 )}

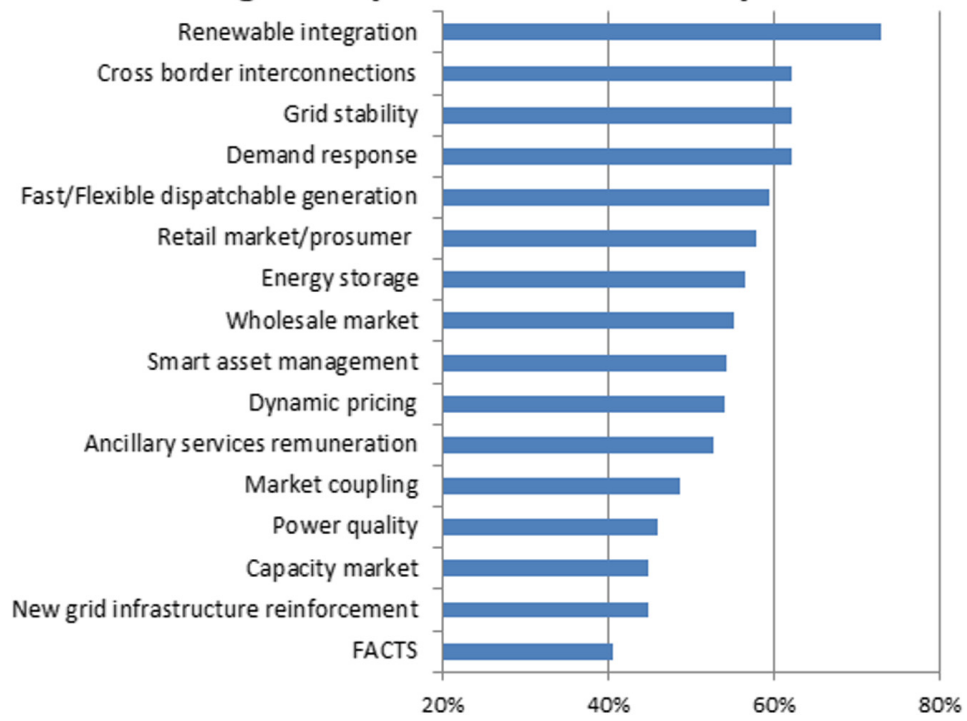

Fig. 5. Percentage of number with high relevance, according to stakeholders, over total answers on critical topics related to flexibility, in long (6-10 years) horizon. 
(i) EU countries have already agreed on a new renewable energy target of at least $27 \%$ of final energy consumption in the EU as a whole by 2030 as part of the EU's energy and climate goals for 2030.

(ii) The October 2014 European Council called for interconnection of at least $10 \%$ of installed electricity production in the Member States by 2020, endorsed the $15 \%$ target by 2030 and underlined that they will be both attained via implementation of Projects of Common Interest in energy infrastructure.

Moreover, in short term horizon (up to 5 years) the wholesale markets and the ancillary services remuneration (market related) are highly prioritized as critical topics. In the long term horizon (more than 5 years), energy storage and demand response are rising higher to the prioritization list of critical topics, since they are currently considered rather immature in Europe.

\section{Conclusions}

Power systems will be called upon to host a wide share of RES generation, bringing the flexibility assessment for needs and resources to the forefront. In the conclusions of the questionnaire by FLEXITRANSTORE project, stakeholders are stressing greatly on renewable integration and enhanced interconnections, while they are greatly interested in energy storage and market incentives for investments and innovation. Wholesale markets with flexibility services remuneration are also of great interest among stakeholders. EU-funded project FLEXITRANSTORE is focusing on demonstrating smart grid and market solutions for increasing transmission grid flexibility joining the efforts of academics, technology providers, industry, market and networks operators.

Acknowledgment. This project has received funding from the European Union's Horizon 2020 research and innovation programme under grant agreement No. 774407.

\section{References}

1. Ulbig, A.: Operational flexibility in electric power systems. Ph.D. dissertation EEH, ETH, Zurich, Switzerland, vol. 72, no. 21882, 230 (2014)

2. Fraunhofer-Institute for Wind Energy and Energy System Technology (IWES): The European power system in 2030: Flexibility challenges and integration benefits, pp. 1-88. Agora Energiewende (2015)

3. Holttinen, H., Tuohy, A., Milligan, M., Lannoye, E., Silva, V., Muller, S., Soder, L.: The flexibility workout: managing variable resources and assessing the need for power system modification. IEEE Power Energy Mag. 11(6), 53-62 (2013)

4. Ecofys: Flexibility options in electricity systems; Project number: POWDE14426, 10 March 2014. www.ecofys.com

5. Lannoye, E., Flynn, D., O’Malley, M.: Transmission, variable generation, and power system flexibility. IEEE Trans. Power Syst. 30(1), 57-66 (2015)

6. $\mathrm{Wu}, \mathrm{L}$., Shahidehpour, M., et al.: Stochastic security-constrained unit commitment. IEEE Trans. Power Syst. 22(2), 800-811 (2007) 
7. Tuohy, A., Meibom, P., et al.: Unit commitment for systems with significant wind penetration. IEEE Trans. Power Syst. 24(2), 592-601 (2009)

8. ENTSOe: MAF 2018 - Mid-term Adequacy Forecast (2018)

9. Chen, H., Baker, S., Benner, S., Berner, A., Liu, J.: PJM integrates energy storage: their technologies and wholesale products. IEEE Power Energy Mag. 15(5), 59-67 (2017)

10. Fyer, J., Corey, G.: Energy storage for the electricity grid: benefits and market potential assessment guide. Sandia National Laboratories, SAND2010-0815 (2010)

11. Sustainable Places Conference. http://www.sustainableplaces.eu/

12. Gaillac, L., et al.: Tehachapi Wind Energy Storage Project: Description of operational uses, system components, and testing plans. In: IEEE PES T\&D 2012, Orlando, FL, USA (2012)

13. www.epri.com

14. www.iea.org

Open Access This chapter is licensed under the terms of the Creative Commons Attribution 4.0 International License (http://creativecommons.org/licenses/by/4.0/), which permits use, sharing, adaptation, distribution and reproduction in any medium or format, as long as you give appropriate credit to the original author(s) and the source, provide a link to the Creative Commons license and indicate if changes were made.

The images or other third party material in this chapter are included in the chapter's Creative Commons license, unless indicated otherwise in a credit line to the material. If material is not included in the chapter's Creative Commons license and your intended use is not permitted by statutory regulation or exceeds the permitted use, you will need to obtain permission directly from the copyright holder.

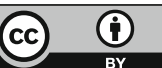

